Jahangirnagar University J. Biol. Sci. 9(1 \& 2): 79-89, 2020 (June \& December)

\title{
In vitro antioxidant activity of the methanolic extract of leaves of a hill tract plant Begonia roxburghii
}

\author{
Taslima Akter*, Afra Nawar, Md. Nur Alam and Md. Rafiquzzaman \\ Department of pharmacy, Jahangirnagar University, Savar, Dhaka-1342 \\ Bangladesh
}

\begin{abstract}
The study was designed to investigate the antioxidant activities of the methanolic extract of leaves of Begonia roxburghii by five different in vitro methods namely Folin-Ciocalteu, total flavonoid content, phosphomolybdenum, total reducing power determination, and DPPH scavenging activity. Phenol content (Gallic acid equivalent) was found as $180.40 \pm 0.03 \mathrm{mg} / \mathrm{g}$ of the dry sample by the Folin-Ciocalteu method. Flavonoid assay method revealed the content of flavonoids (Quercetin equivalent) as $60.43 \pm 0.27 \mathrm{mg} / \mathrm{g}$ of the dry sample. Total antioxidant capacity of the extract was observed $243.43 \pm 0.11 \mathrm{mg} / \mathrm{g}$ ( ascorbic acid equivalent) by phosphomolybdenum method. Free radical scavenging activity (measured by the DPPH test) of the methanolic extract was found $158.36 \pm 0.22 \mu \mathrm{g} / \mathrm{mL}$ whereas ascorbic acid, the standard, showed $19.53 \pm 0.04 \mu \mathrm{g} / \mathrm{mL}$. The methanolic extract of Begonia roxburghii leaves exhibited positive and linear dose dependent reducing power activity and its activity was comparable to the standard ascorbic acid for a given dose. Phytochemical screening of the extract showed positive results for alkaloids, carbohydrates, flavonoids, glycosides, saponins, steroids, and tannins, which demonstrate definite pharmacological actions on human body. The extract showed negative results for the steroids.
\end{abstract}

Key words: Begonia roxburghii, Methanolic extract, Antioxidant.

\section{INTRODUCTION}

The use of medicinal herb for curing diseases has been documented in the history of medicinal science. Before the modern era, men were completely dependent on medicinal herbs for prevention and treatment of diseases (Ghani, 2003). Scientists are thinking that about two-thirds of the world's plant species have medicinal properties and almost all of these have antioxidant potential. (Krishnaiah et al., 2011)

These medicinal plants are being continuously screening by scientists for discovering novel drugs (Hossain, et al., 2018). World Health Organization (WHO) has observed about 20,000 plant species are being used as drugs (IIcim et al., 1998). Primary health care system is mostly dependent on these medicinal plants in Bangladesh. Bangladesh has been very rich in biodiversity and it has more than 500 medicinal plants. (Ghani, 2003). Oxidative stress has been identified as the key factor for the development and progression of several diseases. Plants have long been a source of exogenous (i.e. dietary) antioxidants (Ansari et al., 2017). Natural antioxidants have been allowed as preventive medicines for different diseases. Free radicals are responsible for different diseases, like

\footnotetext{
*Corresponding author. Email: akter_taslima15@yahoo.com
} 
arteriosclerosis, ischemia-reperfusion injury etc. (Bulkley, 1983; Dormandy, 1983; Niki, 1995). Again, several human chronic diseases, such as atherosclerosis, cardiovascular diseases, mutagenesis, cancers, neurodegenerative disorders and the aging process are results of excessive oxidative stress (Frei, 1999). Antioxidants can be synthesized in vivo (e.g. reduced glutathione (GSH), superoxide dismutase (SOD) etc.) or taken as dietary antioxidants (Halliwell, 2007; Sies, 1997).

The interest in the exogenous plant antioxidants was first evoked by the discovery and subsequent isolation of ascorbic acid from plants (Szent-Giörgyi, 1963). Since then, the antioxidant potential of plants has received a great deal of attention. Synthetic antioxidants like butylated hydroxyanisole (BHA), butyl hydroxytoluene (BHT), and tertbutylhydroquinone are used in food and cosmetic industries (Ekrem \& IIhami, 2008). Antioxidants function to provide cell protection against free radicals produced in response to environmental stress such as salinity, drought, high light intensity, and mineral nutrient deficiency (Ashraf \& Harris, 2004). The use of anti-oxidant is increasing in different sectors such as food and beverage industry, cosmetic industry, nutrition and supplement industry because it is proven that antioxidants fight against oxidative damage.

Begonia roxburghii DC is a kind of herbal medicinal plant from Begoniaceae family. It is also known as East Himalayan Begonia as they are highly available in the Himalayan region of India, Nepal and Indo-china. In Bangladesh its common name is Khatredoi and this name is derived from chakma language. In Bangladesh Begonia roxburghii grows in the shady moist places of Chittagong hill tracts regions (Rahman, 1996). The feature which differentiates this plant from other species of Begoniaceae family is the red pigmented dots over the ascending axis of the plant. The leaves and roots of Begonia roxburghii are widely used in the treatment of tongue abnormalities, diarrhea, dysentery and jaundice (Hossain et al., 2013; Rahman, 1996; Tag et al., 2012).

Development of new drug is as a complex, time consuming and an expensive process. Natural products and their derivatives represent more than 50 percent of all the drugs in modern therapeutics (Tag et al., 2012). But still there is a demand to discover new drugs. Earlier preliminary phytochemicals, analgesic, anti-arthritic, thrombolytic and cytotoxic activities of Begonia roxburghii were studied (Hosne et al., 2018) but there is no report on its antioxidant potential though there are currently, approximately, 19 in vitro and 10 in vivo methods available for assessing antioxidant activity of plant samples (Alam et al., 2013). That is why this study was designed to investigate the antioxidant potential of the leaves of Begonia roxburghii by using five different in vitro methods. However, it is important to mention here that at the time of preparation of this manuscript an unpublished project report (Fowzia, 2013) on the extract of Begonia roxburghii leaves was noticed by the authors of the manuscript. Since it was not published in a peer reviewed journal, the author of the present work disregarded the data pertinent to antioxidant activity of that project report. Besides the major aim of investigating antioxidant potential, the authors planned to screen phytochemicals too of the leaves of Begonia roxburghii to verify and to see the compliance of the screened results of this study with the reported earlier (Hosne et al., 2018). 


\section{MATERIALS AND METHODS}

Plant Materials: Leaves of Begonia roxburghii were collected from Chittagong, Bangladesh. The leaves were then sent to the Bangladesh national herbarium (access number 46521) for identification and confirmation and upon their confirmation that the collected leaves were of Begonia roxburghii, those were considered for methanolic extract preparation.

Extraction: The collected and identified leaves were washed to remove dirt and then dried in the sun. The dried samples were ground to coarse powder with a mechanical grinder. The grinder was thoroughly cleaned before grinding of the dried leaves, to avoid contamination with any previously ground material or other foreign matter deposited on the grinder. An air tight glass jar with plastic cover was taken and washed thoroughly, the jar was rinsed with methanol and it was allowed to dry. The prepared coarse powder of the Begonia roxburghii leaves was taken into the jar. Sufficient amount of methanol was added so that the sample was submerged. This jar was kept for 4 days at room temperature and was shaken time to time for better extraction from the powder of the leaves. The soaked material was filtered after four (4) days and the filtrate was dried on an electrical water bath at $70^{\circ} \mathrm{C}$ temperature to remove the solvent methanol completely. The dried extract thus obtained was kept in pre-cleaned glass vials for experiment purposes.

Chemicals and Reagents: Ascorbic acid, Folin-Ciocalteu, quercetin, gallic acid and 1,1diphenyl-2-picryl-hydrazyl (DPPH) were purchased from Sigma Co. (MO, USA). Other chemicals and reagents were of analytical grade.

Phytochemical screening: The methanolic extract of the leaves of Begonia roxburghii was screened by the established methods (Tiwari et al., 2011) for the identification of certain phytochemicals like alkaloids, carbohydrates, flavonoids, glycosides, saponin, steroids, and tannin which are secondary metabolites of plants and are considered to have medicinal properties.

Folin-Ciocalteu Method: Folin-Ciocalteu reagent was used to determine total phenols (Folin \& Ciocalteu, 1927). A dilute plant extract $(0.5 \mathrm{~mL}$ of $1: 10 \mathrm{~g} / \mathrm{mL}$ diluted with distilled water) was mixed with Folin-Ciocalteu reagent $(5 \mathrm{~mL}, 1: 10$ diluted with distilled water) and aqueous $\mathrm{Na}_{2} \mathrm{CO}_{3}(4 \mathrm{~mL}, 1 \mathrm{M})$. The mixture was kept for 15 minutes and the total phenol content was estimated by colorimetry at $765 \mathrm{~nm}$. In this experiment gallic acid was used as standard phenolic compound. The standard curve was prepared using 0 , $50,100,150,200,250 \mathrm{mg} / \mathrm{l}$ solutions of gallic acid in methanol: water $(50: 50, \mathrm{v} / \mathrm{v})$.

Determination of Flavonoid content: The content of flavonoid was determined using Aluminum Chloride colorimetric method (Chang et al., 2002). The plant extract $(0.5 \mathrm{~mL}$ of $1: 10 \mathrm{~g} / \mathrm{mL}$ ) in methanol was mixed with $1.5 \mathrm{~mL}$ of methanol, $0.1 \mathrm{~mL}$ of $10 \%$ Aluminum Chloride, $0.1 \mathrm{~mL}$ of $1 \mathrm{M}$ potassium acetate and $2.8 \mathrm{~mL}$ of distilled water. It was allowed to stand for 30 minutes at room temperature. The absorbance of this mixture was measured at $415 \mathrm{~nm}$. 
Phosphomolybdenum method: It is used to determine total antioxidant capacity of a sample. The phosphomolybdenum method is based on the reduction of Mo (VI) to Mo (V) by the extract and subsequent formation of a green phosphate/Mo (V) complex at acidic pH (Prieto et al., 1999). The antioxidant capacity is expressed as ascorbic acid equivalent (AAE). The plant extract $(0.3 \mathrm{~mL})$ was combined with $3 \mathrm{~mL}$ of reagent solution $(0.6 \mathrm{M}$ sulfuric acid, $28 \mathrm{mM}$ sodium phosphate and $4 \mathrm{mM}$ ammonium molybdate). This mixture was incubated at $95{ }^{\circ} \mathrm{C}$ for 90 minutes. Then the mixture had been cooled to room temperature. The absorbance of the solution was measured at $695 \mathrm{~nm}$ against blank.

DPPH Scavenging activity: DPPH scavenging activity of the plant extract was measured using a method developed by (Manzorro et al., 1998). $2 \mathrm{~mL}$ of DPPH solution $(0.5 \mathrm{mM}$ ) was added to the sample extract $(0.2 \mathrm{~mL})$ which was diluted with methanol. This mixture was kept for 30 minutes and then the absorbance was taken at $517 \mathrm{~nm}$. The percentage of the DPPH radical scavenging value was calculated.

Determination of Total Reducing power: The reducing power of the sample extract was determined following the method of (Oyaizu M. 1986). $10 \mathrm{mg}$ of extract in $1 \mathrm{~mL}$ of distilled water was mixed with phosphate buffer $(2.5 \mathrm{~mL}, 0.2 \mathrm{M}, \mathrm{pH} 6.6)$ and potassium ferric-cyanide $\left[\mathrm{K}_{3} \mathrm{Fe}(\mathrm{CN})_{6}\right](2.5 \mathrm{~mL}, 1 \%)$. It was incubated at $50{ }^{\circ} \mathrm{C}$ for 20 minutes. 2.5 $\mathrm{mL}$ of tri-chloroacetic acid (10\%) was then added to the mixture and centrifuged at 3000 $\mathrm{rpm}$ for 10 minutes. The upper layer of the solution $(2.5 \mathrm{~mL})$ was mixed with distilled water $(2.5 \mathrm{~mL})$ and $\mathrm{FeCl}_{3}(0.5 \mathrm{~mL}, 0.1 \%)$. After that the absorbance was measured at 700 nm. Ascorbic acid was used as reference compound in this experiment. All the experiments were done in triplicate and the mean result was calculated.

\section{RESULTS AND DISCUSSION}

The qualitative phytochemical screening was performed by the standard procedures (Tiwari et al., 2011) and the results have been presented in the (Table 1). It is evident from the Table 1 that the extract of leaves of Begonia roxburghii contains alkaloids, carbohydrates, flavonoids, glycosides, saponin and Tannin but it does not contain steroids. The results are in line with the findings of the Hosne (2018) except flavonoid content, which Hosne M. found much more. 
Table 1. Results of phytochemical screening of the extract of Begonia roxburghii leaves

\begin{tabular}{c|c}
\hline Name of the constituents & Present (+)/Absent (-) \\
\hline Alkaloids & + \\
Carbohydrates & + \\
Flavonoids & + \\
Glycosides & + \\
Saponins & - \\
Steroids & + \\
Tannins & + \\
\hline
\end{tabular}

Total phenols content values are expressed in terms of the reference Gallic acid equivalent i.e. as $\mathrm{mg}$ of Gallic acid/g of the dry mass of the sample. Total phenol content of the extract was calculated from the regression equation $\left(y=0.0102 x-0.0079 ; R^{2}=\right.$ 0.9991) obtained from the calibration curve (Fig. 1) of the standard, gallic acid. In the present study, the assay was done in triplicate. The total phenol content of methanolic extract of Begonia roxburghii leaves was found as $180.40 \pm 0.03 \mathrm{mg} / \mathrm{g}$ (gallic acid equivalent) of dry mass of the sample (Table 2). Hence, it is evident that Begonia roxburghii leaves are good source of phenolic compounds.

Plant phenolic compounds are one of the vital group of phytochemicals that exhibits primary antioxidant property. Begonia roxburghii leaves having plenty polyphenolic compounds, $180.40 \pm 0.03 \mathrm{mg} / \mathrm{g}$ (gallic acid equivalent) of dry mass of the sample (Table 2), will exert inhibitory effects on mutagenesis and carcinogenesis in humans (Tanaka et al., 1988).

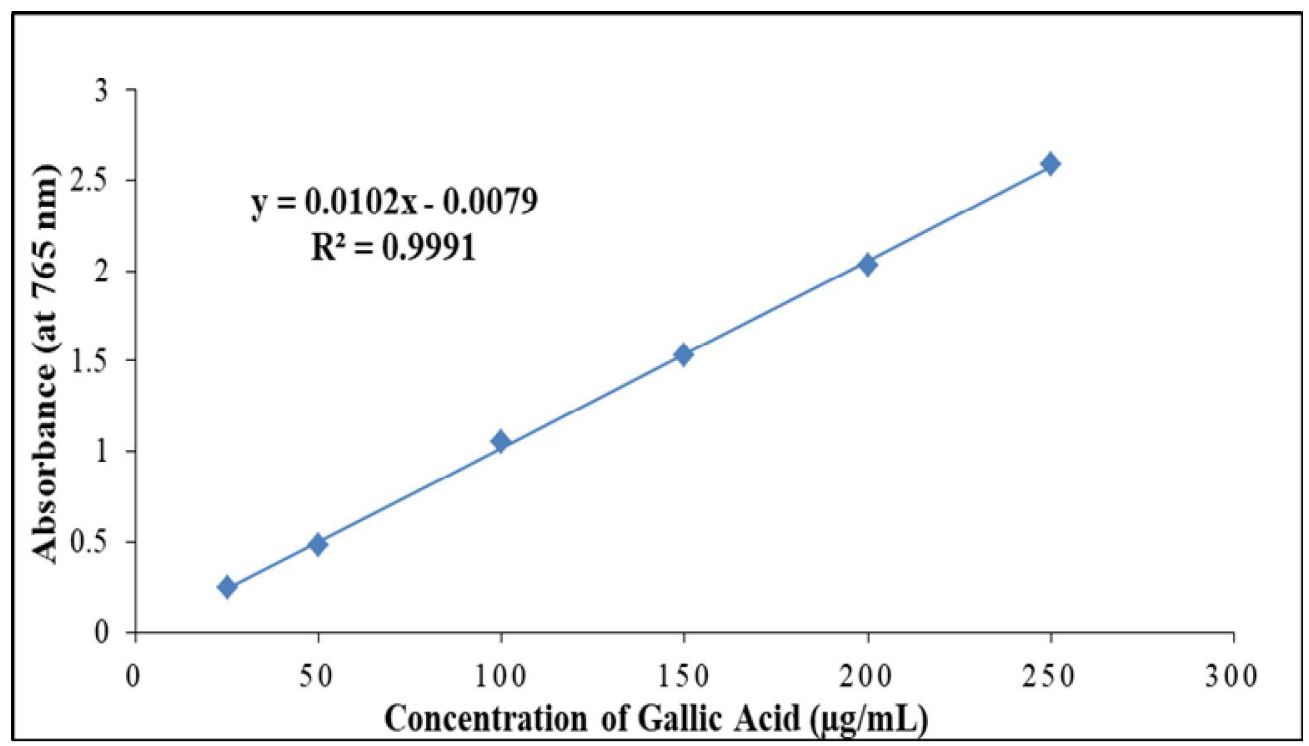

Fig. 1. Calibration curve of Gallic acid 
A calibration curve was made with the absorbance (at $415 \mathrm{~nm}$ ) of the quercetin solutions at concentrations 25 to $200 \mu \mathrm{g} / \mathrm{mL}$ in methanol in order to calculate flavonoid content of the extract from the regression equation $\left(y=0.0057 x-0.0359 ; \mathrm{R}^{2}=0.9693\right)$ corresponding to the calibration curve (not shown). The assay was done in triplicate and the mean value of the content of flavonoid in the extract was $60.43 \pm 0.27 \mathrm{mg} / \mathrm{g}$ (quercetin equivalent) of dry mass of the sample (Table 2), a significant quantity. It was observed (Osawa, 1994) that flavonoid protects coronary heart disease and reduce the incidences of heart attack. Therefore, there is a strong possibility of showing protective effect by the leaves of Begonia roxburghii to coronary heart disease and heart attack because of its flavonoid content (Table 1 and Table 2).

Table 2. Total phenol, total flavonoid and antioxidant content in the extract of the leaves of the Begonia roxburghii

\begin{tabular}{c|c|c}
\hline $\begin{array}{l}\text { Content of representative } \\
\text { antioxidant or antioxidant in the } \\
\text { extract }\end{array}$ & Equivalent to & $\begin{array}{c}\text { mg (of equivalent compound)/g of dry } \\
\text { mass of the sample (mean } \pm \text { SD) }\end{array}$ \\
\hline Total phenol & Gallic acid & $180.40 \pm 0.03$ \\
Flavonoid & Quercetin & $60.43 \pm 0.27$ \\
\hline Total Antioxidant & Ascorbic acid & $243.43 \pm 0.11$ \\
\hline \multicolumn{2}{c}{ (All experiments were performed in triplicate) }
\end{tabular}

The phosphomolybdenum method usually detects antioxidants such as ascorbic acid, some phenolics, tocopherol and carotinoids (Prieto et al.,1999). Antioxidant activity of the extract was calculated from the regression equation $\left(\mathrm{y}=0.0062 \mathrm{x}+0.0288 ; \mathrm{R}^{2}=\right.$ 0.9921 of the calibration curve (not shown), which was constructed from the absorbance of the ascorbic acid (used as a standard) solution in phosphomolybdenum method. The methanolic extract of the leaves of Begonia roxburghii showed moderate antioxidant activity with its total antioxidant value $243.43 \pm 0.11 \mathrm{mg} / \mathrm{g}$ (ascorbic acid equivalent) of the dry mass of the sample (Table 2).

Quantitative ( $\mathrm{IC}_{50} \mu \mathrm{g} / \mathrm{mL}$ ) estimation of DPPH (1,1-diphenyl -2picryl-hydrazyl, a stable free radical) free radical scavenging depends on its ability to be decolorized in the presence of antioxidants (Sadhu et al., 2003). DPPH (containing an odd electron) accepts an electron donated by an antioxidant compound and causes to change its color, which can be quantitatively measured from the changes in absorbance at $517 \mathrm{~nm}$ (Rice-Evans et al., 1997) of the solution being tested.

The $\mathrm{IC}_{50}$ value for the extract was found as $158.36 \pm 0.22 \mu \mathrm{g} / \mathrm{mL}$ whereas for ascorbic acid it was found as $19.53 \pm 0.04 \mu \mathrm{g} / \mathrm{mL}$ (Table 3 and Fig. 2). Therefore, it can be said that Begonia roxburghii leaves extract possesses antioxidant activity but to a lesser extent compared to ascorbic acid. 
Table 3. $\mathrm{IC}_{50}$ value of the methanolic extract of leaves of Begonia roxburghii and ascorbic acid to DPPH free radical scavenging

\begin{tabular}{|c|c|}
\hline Material & $\begin{array}{l}\mathrm{IC}_{50}(\mu \mathrm{g} / \mathrm{mL}) \text { of the material to DPPH free radical } \\
\text { scavenging (mean } \pm \mathrm{SD})\end{array}$ \\
\hline Begonia roxburghii (sample) & $158.36 \pm 0.22$ \\
\hline Ascorbic acid (standard) & $19.53 \pm 0.04$ \\
\hline
\end{tabular}

(All tests were performed in triplicate)

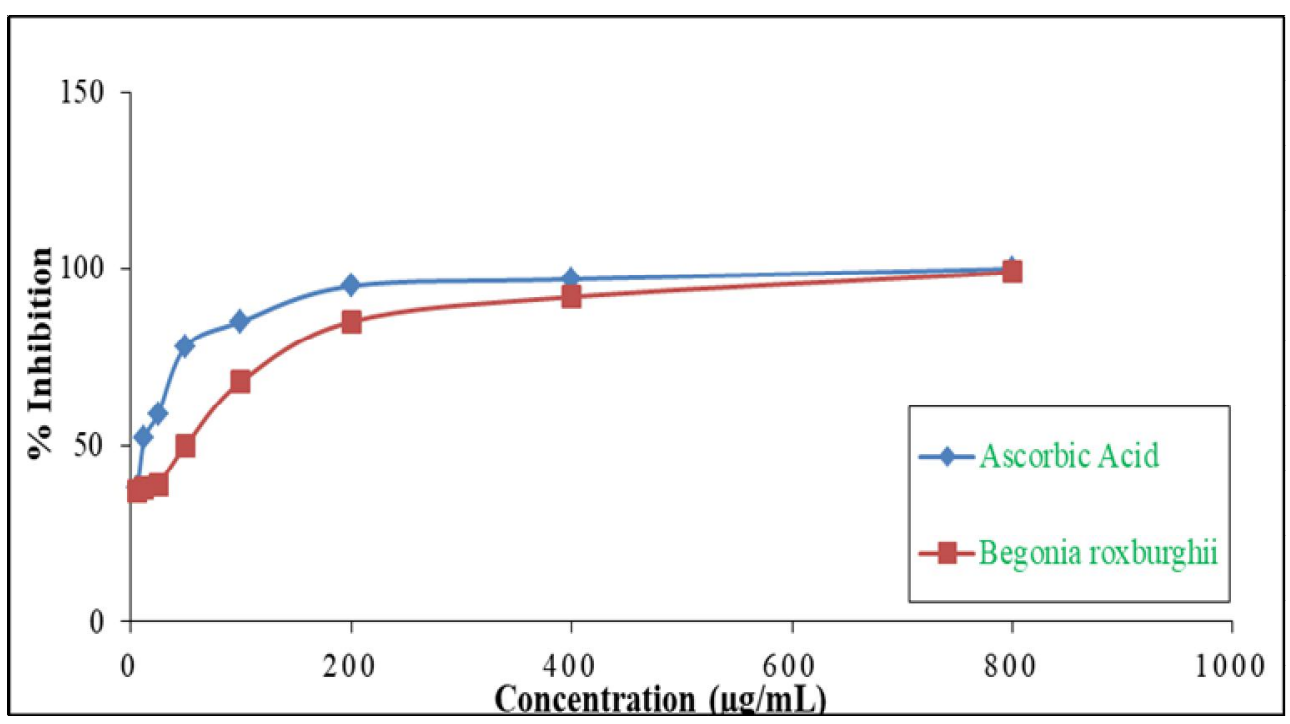

Fig. 2. DPPH free radical scavenging activity of the extract of Begonia roxburghii leaves and ascorbic acid

The percentage of reducing power activity was increased (Table-4) with the increase of the concentration of the extract. It was happened, because antioxidants react with free radicals to convert them into more stable products and thus terminates the radical chain reactions (Tanaka, 1988).

Table 4. Reducing power assessment results of the extract of Begonia roxburghii leaves and the standard ascorbic acid

\begin{tabular}{c|c|c}
\hline Concentration $(\mu \mathrm{g} / \mathrm{mL})$ & $\begin{array}{c}\text { \% reducing power of ascorbic } \\
\text { acid (mean } \pm \text { SD) }\end{array}$ & $\begin{array}{c}\text { \% reducing power of } \\
\text { Begonia roxburghii }(\text { mean } \pm \\
\text { SD) }\end{array}$ \\
\hline 25 & $95 \pm 1.02$ & $38 \pm 2.01$ \\
50 & $118 \pm 0.40$ & $62 \pm 1.13$ \\
100 & $154 \pm 0.90$ & $84 \pm 0.44$ \\
150 & $198 \pm 1.22$ & $123 \pm 2.10$ \\
200 & $290 \pm 0.06$ & $201 \pm 1.80$ \\
\hline
\end{tabular}

(All experiments were performed in triplicate) 


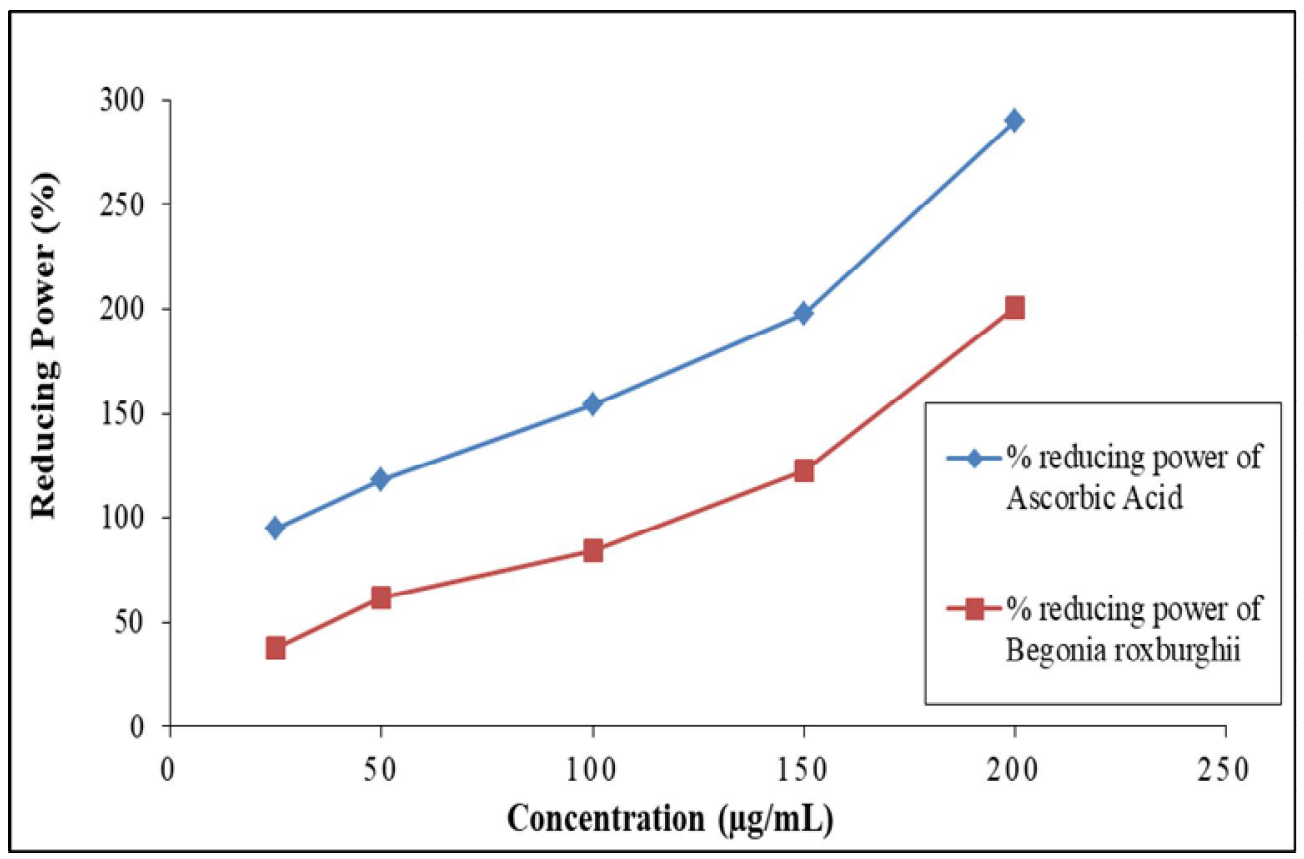

Fig. 3. Comparison of reducing power of ascorbic acid and the methanolic extract of Begonia roxburghii leaves

Reducing power assessment results (Table 4 and Fig. 3) indicated that sample extract showed good or comparable reducing power in relation to the standard ascorbic acid. Reducing power of the extract might be due to hydrogen donating ability of phytochemical from any active present in the extract (Shimada et al., 1992).

An earlier study (Hosne et al., 2018) showed that methanolic extract of leaves of Begonia roxburghii was pharmacologically active. In case of formalin induced pain it was observed that the sample extract inhibited the licking response in both early phase $(56.52 \pm 2.55 \%)$ and the late phase $(62.52 \pm 2.57 \%)$. Again, it was observed that antiarthritic effect performed by protein denaturation method of the extract was concentration dependent. For example, they got maximum inhibition $69.61 \pm 2.15 \%$ at doses 1000 $\mu \mathrm{g} / \mathrm{mL}$. From their study it was also found that the plant extract had $(47.77 \pm 1.80)$ clot lytic activity. They also revealed that leaves extract of the studied plant (Begonia roxburghii) was cytotoxic. Literature review showed that various parts of Begonia roxburghii possesses several medicinal values (Hosne et al., 2018). Medicinal and/or pharmacological activities of Begonia roxburghii as observed by Hosne et al., 2018, and Hossain et al., 2013 might be for the presence of phytochemicals or secondary metabolites of plants like alkaloids, carbohydrates, flavonoids, glycosides, saponin and tannin (Table 1) in Begonia roxburghii (leaves) as it is revealed from the present study. 
Antioxidants are molecules or system capable of inhibiting the oxidation process. They play a vital role in protecting cellular macromolecules from the oxidative damage caused by Reactive Oxygen Species (ROS). Antioxidants also enhance the activity of endogenous enzymes (Osawa, 1994; Loliger, 1991; Wiboonpun et al., 2004). Begonia roxburghii, which contains active phytochemicals (Table 1), and antioxidants (Table 2) is expected to inhibit ROS mediated oxidation of biomolecules and subsequent cell death and tissue damage (Serafina et al., 2010; Nakamura, \& Lipton, 2010; Jomova et al., 2010; Elmarakbly \& Sullivan, 2012) in experimental and biological model, if applied judiciously. Since Reactive Oxygen Species (ROS) cause several degenerative diseases (Kar et al.,2010), Begonia roxburghii may protect the degenerative process through the neutralization of ROS by its antioxidants (Table 2). Several diseases like coronary heart diseases, cancer, atherosclerosis etc. can be prevented by taking antioxidants that scavenge the free radicals (Frei, 1999). Begonia roxburghii leaves could be a good candidate to treat heart diseases, cancer, and atherosclerosis as it contains antioxidants (Table 2) that scavenge the free radicals (Fig. 2 and Table 3).

Conclusion: The present study revealed that Begonia roxburghii leaves contain active plant metabolites - alkaloids, carbohydrates, flavonoids, glycosides, saponin and Tannin. Based on the findings of the current research work, it can be concluded that the methanolic extract of leaves of Begonia roxburghii is a potential source of antioxidants. This work thus provided the scientific basis for the further studies with the various parts, especially the leaves, of the Begonia roxburghii plant to elucidate their nutraceuticals as well as medicinal values or prospective.

\section{REFERENCES}

Alam, M.N., Bristi, N.J. and Rafiquzzaman, M. 2013. Review on in vivo and in vitro methods evaluation of antioxidant activity. Saudi Pharm J. 21:143-152.

Ansari, P., Uddin, M.J., Rahman, M.M., Abdullah-Al-Mamun, M., Islam, M.R., Ali, M.H. and

Reza, A.S. 2017. Anti-inflammatory, anti-diarrheal, thrombolytic and cytotoxic activities of an ornamental medicinal plant: Persicaria orientalis. J Basic Clin Physiol Pharmacol.; 28(1): 51-58.

Ashraf, M. and Harris, P.J.C. 2004. Potential biochemical indicators of salinity tolerance in plants, Plant Science, 166 (1) 3-16.

Atiar, M.R., Rabeya, S., Talha, B.E., Saiful, M.I., Ashiqur, M.R., Joti, S.C., Harun, U.R. and

Chowdhury, M.M.I. 2013. Effects of organic extracts of six Bangladeshi plants on in vitro thrombolysis and cytotoxicity. BMC Complement Altern Med.13(1): 25.

Bulkley, G.B. 1983. The role of oxygen free radicals in human disease processes, Surgery, 94 (3):407-411.

Chang, C., Yang, M. and Wen, H. 2002. Estimation of total flavonoid content in propolis by two complementary colorimetric methods. J. Food Drug Anal., 10: 178-182.

Dormandy, T.L. 1983. An approach to free radicals. Lancet, 2(8357): 1010-1014.

Ekrem, K. and Ilhami, G. 2008 Antioxidant activity of cauliflower (Brassica oleracea L.), Turkish Journal of Agriculture and Forestry, 32(1), 65-78.

Elmarakby, A.A. and Sullivan, J.C. 2012. Relation between oxidative stress and inflammatory Cytokines in Diabetic Nephropathy. Cardiovasc. Ther., 30(1):49-59. 
Folin, O. and Ciocalteu, V. 1927. On tyrosine and tryptophan determination in proteins. J. Biol. Chem., 27: 627-650.

Fowzia, A.C. 2013.http://dspace.bracu.ac.bd/xmlui/bitstream/handle/10361/9340/ID\%2012146031 _PHR.pdf?sequence [Accessed on 5 Sep' 2020]

Frei, B. 1999. On the role of vitamin C and other antioxidants in atherogenesis and vascular dysfunction. Proc Soc Exp Biol Med., 222(3): 196-204

Ghani, A. 2003. Medicinal Plants of Bangladesh, $2^{\text {nd }}$ Ed. The Asiatic Society of Bangladesh Dhaka, Bangladesh, P: 31, 39-40, 418, 500-504, 580-589.

Halliwell, B. 2007. Biochemistry of oxidative stress. Biochem Soc Trans., 35:1147-1150.

Hossain, M.S., Reza, A.A., Rahaman, M.M., Nasrin, M.S., Rahat, M.R.U., Islam, M.R., Uddin,

M.J. and Rahman, M.A. 2018. Evaluation of morning glory (Jacquemontia tamnifolia (L.) Griseb) leaves for antioxidant, antinociceptive, anticoagulant and cytotoxic activities. J Basic Clin Physiol Pharmacol., 29(3): 291-299.

Hosne, M., Mohammed, S.M., Nahid, S., Md. T., Afrina, A., Riniara, K., Mst, S.N., Md, O.R. and Ali Reza, A.S.M. 2018. Investigation of preliminary phytochemicals, analgesic, antiarthritic, thrombolytic and cytotoxic activities of Begonia roxburghii (Miq) DC. Leaves. Med One, 2: 1-12.

IIcim, A., Digrak, M. and Bagci, E. 1998. The investigation of antimicrobial effect of some plant extract. TR. J. Biol., 22: 119-125

Jomova, K., Vondrakova, D., Lawson, M. and Valko, M. 2010. Metals, oxidative stress and neurodegenerative disorders. Mol Cell Biochem. 345 (1-2): 91-104

Kar, S., Subbaram, S., Carrico, P.M. and Melendez, J.A. 2010. Redox control of Matrix Metalloproteinase-1: A critical link between free radicals, matrix remodeling and degenerative disease. Respir Physiol Neurobiol. 174(3):299-306

Krishnaiah, D., Sarbatly, R. and Nithyanandam, R. 2011. A review of the antioxidant potential of medicinal plant species. Food Bioprod Process. 89:217-33.

Loliger, J. 1991. The use of antioxidants in food. In O.I. Aruoma \& B. Halliwell (Eds.), Free radicals and food additives. London, UK: Taylor and Francis, pp 121-150

Manzorro, L., Anese, M. and Nicoli, M.C. 1998. Antioxidant properties of tea extracts as affected by processing. Lebens-mittel-Wissenscaft Und-Technology., 31(7-8):694-698

Nakamura, T. and Lipton, S.A. 2011. S-Nitrosylation of Critical Protein Thiols Mediates protein Misfolding and Mitochondrial Dysfunction in Neurodegenerative Diseases. Antioxide Redox Signal 14(8):1479-1492

Niki, E. 1995. Antioxidants, Free radicals and biological defence. In: Niki E., Shimasaki H.,\& Mino, M. (Eds.), Japan Scientific Society Press, Tokyo, pp.3

Osawa, T. 1994. Novel natural antioxidants for utilization in food and biological systems. In: Uritani I., Garcia V.V. \& Mendoza E.M. (Eds) Post harvest biochemistry of plant food materials in the tropics. Japan Scientific Societies Press, Tokyo, pp.241-251

Oyaizu, M. 1986. Antioxidative activities of products of browning reaction prepared from Glucosamine, Jap J.Nutr. 44 : 307-331

Prieto, P., Pineda, M. and Aguilar, M. 1999. Spectrophotometric quantitation of antioxidant capacity through the formation of a phosphomolybdenum complex: Specific application to the determination of vitamin E, Analytical Biochemistry, 269: 337-341

Rahman, M. 1996. Diversity, ecology and ethnobotany of the Zingiberaceae of Bangladesh. $J$ Econ Taxon Bot Addl Series. 12: 13-19.

Rice-Evans, C., Sampson, J., Bramley, P.M. and Holloway, D.E. 1997. Why do we expect carotinoids to be antioxidants in vivo. Free Radical Res.26: 381-398 
Sadhu, S.K., Okuyama, E., Fujimoto, H. and Ishibashi, M. 2003. Separation of Leueas aspera, a medicinal plant of Bangladesh, Guided by Prostaglandin Inhibitory and Antioxidant Activities. Chem Phan Bull. 51(5): 595-598

Serafina, P., Simona, N., Maria, L.T. and Giuseppe, B. 2010. Oxidative stress and antioxidant strategies in newborns. J Matern Fetal Neonatal Med., 3: 63-65.

Shimada, K., Fujukawa, K., Yahara, K. and Nakamura, T. 1992. Anti-oxidative properties of xanthan on the auto-oxidation of soybean oil in cyclodextrin emulsion. J. Agric. Food Chem, 40: $945-948$

Sies, H. 1997 Oxidative stress: oxidants, antioxidants. Exp Physiol. 82:291-95.

Szent-Giörgyi, A. 1963. Lost in the twentieth century. Annu Rev Biochem. 36:1-15.

Tag, H., Kalita, P., Dwivedi, P., Das, A. and Namsa, N.D. 2012. Herbal medicines used in the treatment of diabetes mellitus in Arunachal Himalaya, northeast, India. $J$ Ethnopharmacol. 141(3): 786-795.

Tanaka, M., Kuie, C.W., Nagashima, Y. and Taguchi, T. 1988. Applications of antioxidative Maillard reaction products from histidine and glucose to sardine products. Nippon suisan Gakaishi., 54:1409-1414.

Tiwari, P., Kumar, B., Kaur, M., Kaur, G., Kaur, H. 2011. Phytochemical screening and extraction: a review. Int Pharm Sci.; 1(1): 98-106.

Wiboonpun, N., Phuwapraisirisan, P. and Tip-pyang, S. 2004. Identification of antioxidant compound from Asparagus racemosus. Phytotherapy Res. 18: 771-773. 